\title{
Identifikasi Potensi Pengembangan Lanskap Wisata Pertanian di Kawasan Kedung Kayang Kabupaten Magelang
}

\author{
DOI 10.18196/pt.2015.044.87-93
}

\author{
Lis Noer Aini \\ Program Studi Agroteknologi, Fakultas Pertanian, Universitas Muhammadiyah Yogyakarta, \\ Jl. Lingkar Selatan, Kasihan, Bantul, Yogyakarta 55183, Indonesia, Telp. 0274387656, \\ e-mail: nenny@umy.ac.id
}

\begin{abstract}
ABSTRAK
Penelitian ini bertujuan mengidentifikasi potensi pengembangan Kedung Kayang sebagai daerah agrowisata untuk meningkatkan kesejahteraan masyarakat Kedung Kayang dan sekitarnya. Penelitian ini menggunakan metode survey dengan metode observasi dan kuesioner. Data primer maupun sekunder dianalisis secara deskriptif dan spasial, Data primer terdiri dari persepsi tentang Kedung Kayang, sementara data sekunder meliputi peta wilayah Magelang, letak geografis, jenis tanah, topografi, kondisi iklim dan sosial masyarakat Kedung Kayang dan sekitarnya. Hasil penelitian menunjukkan bahwa wilayah Kedung Kayang memiliki potensi alam seperti air terjun, pemandangan Gunung Merapi, sungai, topografi, bumi perkemahan dan potensi pertanian. Hasil identifikasi menunjukkan bahwa Kedung Kayang berpotensi menjadi daerah agrowisata.
\end{abstract}

Kata kunci: Identifikasi potensi, Agrowisata, Kedung Kayang

\section{ABSTRACT}

The research aims to identify the development potential of Kedung Kayang as agritourism area to increase society welfare Kedung Kayang and vinicity. The method of this research was survey method by using observation and questioner. The data were analyzed descriptively and spatially, with primary and secondary data. Primary data consisted of perception about Kedung Kayang, while secondary data consisted of Magelang map, geographical position, soil kind, topography, climate and society social condition of Kedung Kayang and vinicity. The result of this research showed that Kedung Kayang area has natural potential i.e: waterfall, Merapi view, river, topograph, camping ground, and agricultural potential. The result of identification showed that Kedung Kayang has potential to be an agrotourism area.

Keywords: Potential identification, Agritourism, Kedung Kayang

\section{PENDAHULUAN}

Magelang merupakan salah satu kabupaten di Indonesia yang mempunyai potensi wisata yang cukup tinggi. Peninggalan sejarah dan kondisi alam yang indah, menyebabkan kabupaten ini menjadi salah satu primadona wisata di Indonesia. Hal ini terlihat dari data tingginya jumlah wisatawan baik wisatawan nusantara maupun wisatawan mancanegara yang datang ke Magelang pada tahun 2006 terdapat 821.762 wisatawan, serta pada tahun 2007 meningkat mencapai 937.676 wisatawan (www.suarakarya. com, 2007). Peningkatan tersebut tak lepas dari dayatarik yang tinggi dan didukung oleh keamanan dan kenyamanan obyek wisata. Selain itu, kondisi sosial ekonomi wisatawan yang cenderung membaik menjadi faktor penting dalam upaya meningkatkan kunjungan wisatawan.

Kawasan Kedung Kayang merupakan kawasan kaki Gunung Merapi yang terletak di Desa Wonolelo Kecamatan Sawangan Magelang Jawa Tengah. Lokasi yang terletak $3 \mathrm{~km}$ dari Gardu Wisata Ketep Pass ini dilatarbelakangi view Gunung Merapi. Kedung Kayang juga memiliki air terjun dengan tinggi 40 m., serta memiliki medan terjal yang menantang (www.pemkab, magelang.go.id, 2002). Adanya potensi pertanian dan potensi alam yang meliputi bumi perkemahan serta daerah pegunungan dengan pemandangan alam yang indah dan udara yang sejuk dapat membuat suasana nyaman bagi wisatawan dan menambah daya tarik di wisata Kedung Kayang.

Selain mempunyai potensi wisata alam yang 
cukup indah dan tidak kalah menarik dengan potensi wisata alam yang ada di Magelang, kawasan ini mempunyai sumber daya alam yang sangat memadai yaitu adanya penyimpanan kandungan lengas air di dalam tanah dan tanah yang subur, sehingga dapat memaksimalkan hasil pertanian terutama untuk mengembangkan komoditas-komoditas yang ditunjukkan pada Tabel 1. Banyaknya hasil-hasil pertanian unggulan seperti cabe merah, kobis, buncis di kawasan Kedung Kayang dapat menjadikan kawasan ini berpotensi untuk pengembangan Agrowisata. Selain itu juga terdapat komoditas lain di kawasan Kedung Kayang seperti stroberi.

Tabel 1. Pengaruh Cairan Pembersih Lumut dan Pupuk Anorganik terhadap Jumlah Tunas

\begin{tabular}{|c|c|c|c|c|c|}
\hline \multirow{4}{*}{ No. } & \multirow{4}{*}{$\begin{array}{c}\text { Jenis } \\
\text { Komoditas }\end{array}$} & \multicolumn{4}{|c|}{ Tahun } \\
\hline & & \multicolumn{2}{|c|}{2004} & \multicolumn{2}{|c|}{2005} \\
\hline & & \multicolumn{2}{|c|}{ Luas } & \multicolumn{2}{|c|}{ Luas } \\
\hline & & $\begin{array}{c}\text { Panen } \\
(\mathrm{Ha})\end{array}$ & $\begin{array}{l}\text { Produksi } \\
(\mathrm{Kw})\end{array}$ & $\begin{array}{c}\text { Panen } \\
(\mathrm{Ha})\end{array}$ & $\begin{array}{c}\text { Produksi } \\
(\mathrm{Kw})\end{array}$ \\
\hline 1. & Wortel & 27 & 2.869 & 31 & 2.387 \\
\hline 2. & Kacang Panjang & 80 & 3.226 & 74 & 3.551 \\
\hline 3. & Ketimun & 25 & 6.025 & 37 & 8.338 \\
\hline 4. & Cabe Merah & 231 & 15.140 & 203 & 15.110 \\
\hline 5. & Tomat & 189 & 28.043 & 182 & 29.944 \\
\hline 6. & Padi sawah & - & - & 3,43 & 51,10 \\
\hline 7. & Jagung & 365 & 255.500 & 1,08 & 46,18 \\
\hline 8. & Kentang & 19 & 3.436 & 54 & 10.837 \\
\hline 9. & Kobis & 185 & 33.206 & 196 & 36.551 \\
\hline 10. & Sawi & 70 & 8.503 & 42 & 5.184 \\
\hline 11. & Terong & 38 & 3.525 & 47 & 5.093 \\
\hline 12. & Buncis & 87 & 6.040 & 103 & 9.908 \\
\hline
\end{tabular}

Sumber : Monografi Desa Wonolelo pada tahun 2005

Selain kegiatan pertanian, kehidupan sosial masyarakat di wilayah ini cukup baik dan sangat kondusif. Hal ini ditunjukkan dari sikap masyarakat yang menekankan pada prinsip kerukunan, tolong menolong, dan gotong royong menjadi modal dasar yang sangat penting bagi pengembangan kawasan ini.

Berdasarkan penjelasan-penjelasan di atas dik- etahui bahwa kawasan Kedung Kayang memiliki potensi sangat besar untuk dijadikan kawasan agrowisata, oleh karena itu perlu dilakukan penelitian lebih lanjut tentang identifikasi potensi wisata Kedung Kayang sehingga dapat memudahkan dalam pengembangan kawasan Kedung Kayang menjadi kawasan Agrowisata.

\section{BAHAN DAN METODE}

Penelitian dilakukan menggunakan metode survei, yang teknis pelaksanaannya dilakukan dengan observasi, kuesioner dan pengumpulan data sekunder dianalisis secara deskriptif dan spasial. Analisis deskriptif dimaksudkan untuk memberikan penjelasan dan uraian berdasarkan data dan informasi yang diperoleh selama penelitian. Menurut Nawawi (1995), metode deskriptif diartikan sebagai prosedur pemecahan masalah dengan menggambarkan keadaan subyek/obyek penelitian berdasarkan fakta-fakta yang tampak dan usaha mengemukakan hubungan satu dengan yang lain di dalam aspek yang diselidiki. Sementara analisis spasial dilakukan untuk membuat zonasi kawasan berdasarkan potensi yang diperoleh. Observasi dilakukan untuk mendapatkan informasi tentang kondisi eksisting wilayah, yang akan menggambarkan kondisi kawasan tersebut. Hal-hal yang menjadi perhatian dalam observasi ini adalah identifikasi potensi, pemanfaatan lahan, keadaan alamiah kawasan pegunungan dan kondisi sosial. Data yang akan diperoleh dalam observasi ini berupa data kualitatif dan gambaran umum serta hasil pemotretan yang dapat mewakili kondisi wilayah keseluruhan.

Pengambilan sampel responden dilakukan dengan metode Stratifid random sampling, yaitu Stratifid artinya strata atau kedudukan subjek (seseorang) di masyarakat, digunakan untuk mengetahui beberapa variabel pada populasi 
yang merupakan hal yang penting untuk mencapai sampel yang representatif. Selanjutnya dengan menggunakan metode purposive, yaitu pengambilan sempel dengan sengaja dipilih dari populasi berdasarkan tujuan penelitian. Penyebaran kuesioner dilakukan dengan memberikan sejumlah daftar pertanyaan kepada penduduk setempat, pedagang, pengelola, pengunjung Kedung Kayang dan pengunjung di obyek wisata Ketep Pass yang berjumlah 150 kuisioner akan tetapi yang terisi hanya 101 kuisioner, ini dikarenakan ada responden yang tidak mau mengisi, dengan asumsi dapat mewakili sifat populasi secara keseluruhan. Hasil observasi dan penyebaran kuesioner perlu didukung oleh data mengenai batas-batas wilayah, luas, ketinggian tempat, topografi, iklim, jenis tanah, suhu udara, hari hujan, curah hujan, kecepatan angin, kondisi sosial masyarakat yang dicatat dalam angka serta peta, sehingga memperkuat gambaran sosial masyarakat dan kondisi geografis wilayah. Data sekunder yang diperlukan diperoleh dari instansi terkait, diantaranya BAPPEDA dan Dinas Pariwisata.

\section{HASIL DAN PEMBAHASAN}

\section{Kondisi Fisik Kawasan Kedung Kayang}

Kedung Kayang merupakan kawasan pegunungan yang terletak di Desa Wonolelo, Kecamatan Sawangan, Kabupaten Magelang. Kondisi topografis Kedung Kayang merupakan cekungan yang dikelilingi oleh dua gunung yaitu Gunung Merbabu dan Merapi

Topografi kawasan ini mulai dari landai hingga berbukit dan bergunung-gunung. Kondisi lingkungan fisik Kedung Kayang dan sekitarnya, terdiri dari 2 wilayah berdasarkan perbedaan relief medannya, yaitu di sebelah utara terdapat dataran tinggi yang menyempit di antara dua buah gunung, yakni Gunung Merapi dan Gu- nung Merbabu. Kondisi ini menjadikan sebagian besar wilayahnya merupakan lahan subur karena berlimpahnya sumber air dan sisa abu vulkanik. Oleh karena itu tidak mengherankan jika Kedung Kayang mempunyai potensi pertanian yang subur. Bagian selatan, lereng Merapi terus turun dan melandai hingga ke pantai selatan di tepi Samudera Hindia, melintasi wilayah kota Yogyakarta. Sebelum kaki gunung, terdapat dua bukit yaitu Bukit Turgo dan Bukit Plawangan yang merupakan bagian kawasan wisata Kaliurang serta terdapatnya 1.350,6 hektar hutan Negara (Pemda. Sawangan, 2006).

Tanah yang berada di kawasan Kedung Kayang didominasi oleh tanah litosol coklat dan andosol coklat, seperti kebanyakan daerahdaerah di lereng gunung di Indonesia. Dengan kandungan unsur hara yang cukup tinggi, sistem pertanian yang dilakukan bisa lebih dari satu macam, yaitu dengan sistem monokultur maupun dengan sistem tumpang sari.

Kondisi alam yang demikian indah tersebut, berdasarkan kajian wisata di Kecamatan Sawangan dapat dikatakan bahwa obyek wisata Kedung Kayang memiliki potensi terbesar atau merupakan daya tarik utama dibanding obyek-obyek wisata di sekitarnya. Suasana alam dapat dinikmati pemandangan alam yang sangat menarik. Salah satu keunikan dari Kedung Kayang adalah view air terjun dan sungai yang dapat terlihat dari bagian atas dan bawah, dan salah satu daya tarik tersendiri bagi wisatawan (Pemda. Sawangan, 2006).

\section{Kondisi Sosial Masyarakat Kedung Kayang}

Penduduk Kedung Kayang sebagian besar bermata pencaharian sebagai petani, baik petani sendiri maupun buruh tani. Jenis tanaman yang dibudidayakan oleh petani Kedung Kayang adalah padi, jagung dan sayur-sayuran (cabe 
merah, kubis, buncis). Usaha pertanian khususnya sayur-sayuran di Kedung Kayang telah dapat memperbaiki kondisi perekonomian masyarakat.

Sebagian besar penduduk Kedung Kayang berpendidikan SD, akibat dari rendahnya pendidikan tersebut penduduk Kedung Kayang keadaan perekonomian atau penghasilan yang didapat tidak terpenuhi secara maksimal. Ketrampilan yang dimiliki sangat rendah sehingga lapangan pekerjaan terbatas, hanya mengandalkan pekerjaan pertanian yang keberadaannya tidak cukup untuk menyejahterakan semua masyarakat Kedung Kayang. Upaya yang dilakukan untuk memperbaiki perekonomian masyarakat melalui pengembangan pertanian dan pendidikan, karena dengan pendidikan diharapkan penduduk Kedung Kayang akan lebih berkualitas. Sementara untuk pengembangan pertanian dapat menonjolkan budaya lokal dalam memanfaatkan lahan, kita bisa meningkatkan kenyamanan, keindahan ataupun pengetahuan petani sambil melestarikan sumber daya lahan, serta memelihara budaya maupun teknologi lokal yang umumnya telah sesuai dengan kondisi lingkungan alami Kedung Kayang.

Selain memberikan nilai kenyamanan, keindahan ataupun pengetahuan, pertanian juga dapat mendatangkan pendapatan bagi petani serta masyarakat di sekitarnya. Adanya kesadaran petani akan arti pentingnya kelestarian sumber daya, kelanggengan produksi menjadi terjaga yang pada gilirannya akan meningkatkan pendapatan petani. Bagi masyarakat sekitar, dengan banyaknya kunjungan wisatawan, mereka dapat memperoleh kesempatan berusaha dengan menyediakan jasa dan menjual produk yang dihasilkan untuk memenuhi kebutuhan wisatawan Kedung Kayang. Akan tetapi, kesulitan yang dihadapi petani daerah Kedung Kayang karena nasib para petani lebih banyak ditentukan oleh pedagang di kota-kota besar yang menentukan harga, sehingga keadaan perekonomiannya belum maksimal. Untuk mengatasi permasalahan tersebut perlu diciptakan pasar bagi produkproduk pertanian, sehingga petani Kedung Kayang dapat mudah dalam usaha penjualan hasil panen dan masyarakat petani Kedung Kayang dapat menentukan harga bahkan wisatawan yang berkunjung akan langsung menjadi konsumen produk pertanian yang dihasilkan, sehingga pemasaran hasil menjadi lebih efisien.

\section{Identifikasi Potensi Lanskap Wisata Kedung Kayang}

Dalam pengelolaan suatu kawasan wisata perlu dilakukan identifikasi untuk mendapatkan suatu rencana kawasan.

\section{Potensi Alam}

Kawasan Kedung Kayang terletak di daerah Pegunungan mulai dari landai hingga berbukit dan bergunung-gunung serta tebing yang terjal. Topografi bergelombang dengan sudut kemiringan antara 30\% hingga 70\%. Ketinggian tempat 600 - 2.968 meter di atas permukaan, dilatarbelakangi oleh dua gunung kembar Merbabu dan Merapi. Kedung Kayang juga mempunyai daya tarik alam berupa tumbuhan, satwa atau ekosistem, gejala alam serta formasi geologi yang menarik, yang terdiri dari batuan dan tanah vulkanik. Dengan kondisi geografis yang beragam seperti ini menjadikan Kedung Kayang memiliki view yang indah serta berhawa sejuk, yang bisa dijadikan potensi wisata utama Kedung Kayang. Di obyek wisata Kedung Kayang ini pariwisata dapat bermain air, menikmati pemandangan, bersantai, menyusuri sungai menuju bawah air terjun atau hanya sekedar menikmati air terjun dari atas saja. Selain itu wisatawan juga dapat melakukan kegiatan berkemah, bagi yang menyukai pertualangan dapat juga melakukan out bond 
di obyek wisata ini.

Air terjun Kedung Kayang berada di kawasan pegunungan dengan view yang indah sejuk dan nyaman, dengan ketinggian air terjun $40 \mathrm{~m}$. Sumber air terjun berasal dari aliran sungai Pabelan yang berasal dari Gunung Merapi dan Gunung Merbabu. Air terjun Kedung Kayang ini memiliki kelebihan yaitu bisa dilihat dari atas dan juga dari bawah dengan jalan yang terjal untuk melihat dari bagian bawah. Adanya mitos di masyarakat bahwa terdapatGoa di belakang air terjun dengan lebar 2 meter dan tinggi 2,5 dengan panjang tak terbatas (tidak dapat diketahui) karena tidak ada ujungnya, serta adanya sungai dan batu-batuan kali di bagian bawah menambah keasrian wisata, kondisi sungai tersebut dapat dikembangkan menjadi wisata pertualangan penyelusuran sungai mulai dari bumi perkemahan sampai air terjun.

Bumi Perkemahan Kedung Kayang memiliki potensi wisata alam karena pemandangan yang indah, udara yang sejuk, dan susunan tanah yang bergelombang sehingga menambah ketertarikan wisatawan untuk melakukan kegiatan camping dan berpotensi untuk dijadikan wisata outbond di sekitar wilayah tersebut

Kondisi alam Kedung Kayang yang demikian indah, meliputi kondisi fisik topograpi mulai dari landai hingga berbukit dan bergununggunung yang membentang mengelilingi kawasan wisata Kedung Kayang dengan view Gunung Merapi dan Gunung Merbabu. Bentuk topografi seperti ini terjadi secara alamiah sehingga keberadaannya merupakan suatu fenomena alam yang menarik yang dapat menjadi daya tarik tersendiri bagi pengunjung. Ketinggian bukit \pm 50 meter dengan kondisi relif dinding yang terjal berpotensi untuk dijadikan wisata panjat tebing dan juga flying fox.

\section{Potensi Sosial}

Daerah Kedung Kayang merupakan daerah potensial untuk sektor pertanian. Tingkat pengetahuan masyarakat akan pengembangan tanaman khususnya tanaman hortikultura cukup baik, hal ini terlihat jenis tanaman yang dihasilkan berupa sayur-sayuran dan buah-buahan seperti stroberi dengan tingkat produksi yang tinggi. Walaupun mayoritas penduduk Kedung Kayang bekerja dalam sektor pertanian, namun penduduk Kedung Kayang masih mendapat tambahan penghasilan dari adanya kegiatan wisata Kedung Kayang, seperti menjadi pedagang.

Tabel 2. Pengetahuan Masyarakat terhadap Wisata Kedung Kayang

\begin{tabular}{|c|c|c|c|c|}
\hline No. & Pengetahuan & $\begin{array}{l}\text { Tanggapan } \\
\text { Masyarakat }\end{array}$ & Jumlah & $\%$ \\
\hline \multirow[t]{2}{*}{1.} & \multirow[t]{2}{*}{ Keberadaan Kedung Kayang } & Tahu & 79 & 78,21 \\
\hline & & Tidak tahu & 22 & 21,78 \\
\hline \multirow[t]{4}{*}{2.} & \multirow[t]{4}{*}{ Kesukaan Berkunjung } & Air terjun & 74 & 55,22 \\
\hline & & Bumi perkemahan & 26 & 19,40 \\
\hline & & Kawasan pertanian & 21 & 15,67 \\
\hline & & Lainnya & 13 & 9,70 \\
\hline \multirow[t]{2}{*}{3.} & \multirow[t]{2}{*}{ Sumber Informasi } & Mudah & 65 & 68,08 \\
\hline & & Sulit & 30 & 31,47 \\
\hline \multirow[t]{2}{*}{4.} & \multirow[t]{2}{*}{ Jalur Akses Menuju Kedung Kayang } & Mudah dijangkau & 64 & 68,08 \\
\hline & & Sulit & 30 & 31,91 \\
\hline \multirow[t]{4}{*}{5.} & \multirow{4}{*}{$\begin{array}{l}\text { Adanya Kendaraan Umum Menuju } \\
\text { Kedung Kayang }\end{array}$} & Ada, dan banyak & 26 & 28,88 \\
\hline & & Ada, tetapi terbatas & 29 & 32,22 \\
\hline & & Tidak ada Lainnya & 5 & 5,55 \\
\hline & & & 10 & 11,11 \\
\hline \multirow[t]{2}{*}{6.} & \multirow[t]{2}{*}{ Akses di Dalam Kawasan } & Mudah & 54 & 56,25 \\
\hline & & Sulit & 42 & 43,75 \\
\hline \multirow[t]{2}{*}{7.} & \multirow[t]{2}{*}{ Perbaikan Fasilitas } & Perlu & 92 & 97,91 \\
\hline & & Tidak perlu & 2 & 2,08 \\
\hline
\end{tabular}

Keberadaan wisata Kedung Kayang di antara wisata lainnya di Kabupaten Magelang, tidak lantas membuat masyarakat Magelang melupakan kehadiran wisata ini. Wisata yang terletak di Desa Wonolelo, Kecamatan Sawangan ini memiliki berbagai potensi fisik dan potensi sosial yang spesifik, menjadikan wilayah ini lebih berkembang pesat untuk kegiatan pariwisata 
dibandingkan wisata alam lain di Magelang. Pengetahuan responden terhadap keberadaan Potensi yang terdapat di kawasan wisata Kedung Kayang disajikan pada Tabel 2.

Potensi fisik di kawasan Kedung Kayang yaitu morfologi kawasan mulai dari bentuk topografi kawasan yang berbukit-bukit karena dilatarbelakangi oleh Gunung Merapi, susunan geologi dan iklimnya. Sementara kondisi sosial meliputi kegiatan yang sering dilakukan secara tradisional, kehidupan masyarakat sekitar kawasan wisata, peran masyarakat dan lain sebagainya.

Kurangnya kepedulian pemerintah setempat akan keberadaan wisata Kedung Kayang membuat penataan kawasaan wisata Kedung Kayang kurang tertangani, sehingga perlu penataan. Berdasarkan Tabel 2 menunjukkan bahwa kawasan wisata Kedung Kayang sudah cukup dikenal yang ditunjukkan dari 78,21 \% dari 101 responden tahu keberadaan Kedung Kayang. Kedung Kayang mempunyai potensi pertanian sayur mayur dan buah-buahan yang unggul, dan potensi alam seperti: wisata air terjun, sungai, bumi perkemahan dan view Gunung Merapi dan Merbabu yang menambah keasrian wisata Kedung Kayang. Obyek yang menarik bagi wisatawan di kawasan wisata Kedung Kayang adalah air terjun 55,22\%, bumi perkemahan 19,4\%, kawasan pertanian 15,67\% dan yang lainnya sebanyak 9,70 \%. Hal ini membuktikan sampai saat ini wisatawan sebagian besar ingin menikmati panorama air terjun dibandingkan dengan yang lainnya.

Di sisi lain 97,91\% responden menginginkan penataan atau perbaikan fasilitas kawasan Kedung Kayang agar kenyamanan dalam berkunjung menjadi sesuatu yang terpuaskan. Penataan kawasan ini dapat dilakukan dengan kepedulian pemerintah dalam penanganan perbaikan kondi- si Kedung Kayang, serta keterlibatan masyarakat setempat dalam pengelolaan wisata Kedung Kayang seperti penataan jalan yang masih terjal untuk menuju lokasi, kebersihan lingkungan, dan penertiban pedagang, sehingga dengan cara ini dapat membuat suasana pengunjung merasa nyaman dan tertata dengan baik.

\section{Potensi Agrowisata}

Kedung Kayang mempunyai potensi untuk dikembangkan menjadi kawasan agrowisata. Aset penting untuk menarik kunjungan wisatawan adalah keaslian, keunikan, kenyamanan, dan keindahan alam dalam bentuk hijaunya sayur mayur yang berada di sekitar kawasan Kedung Kayang. Pertanian hortikultura di sekitar Kedung Kayang turut andil dalam menarik minat pengunjung. Kondisi cuaca yang sejuk membuat pengunjung cukup menikmati panorama sekitar. Tingkat pengetahuan masyarakat akan pengembangan tanaman khususnya tanaman hortikultura cukup baik, hal ini terlihat jenis tanaman yang dihasilkan berupa sayur-sayuran (cabe merah, kubis, buncis) dan buah seperti stroberi dengan tingkat produksi tinggi. Kondisi fisik Kedung Kayang berada di dataran tinggi 1500-2000 $\mathrm{m}$ di atas permukaan laut, curah hujan 2.177 $\mathrm{mm}$, hari hujan $172 \mathrm{hh}$, tipe iklim C, suhu 22$25^{\circ} \mathrm{C}$, kecepatan angin $5,1 \mathrm{~km} / \mathrm{jam}$, jenis tanah litosol coklat dan andosol coklat, berpotensi untuk dikembangkan komoditas buah-buahan dan bunga selain komoditas yang sudah ada di Kedung Kayang dan sesuai dengan kondisi fisik kawasan Kedung Kayang sehingga dapat menambah pendapatan petani dan menambah potensi atau daya tarik untuk dijadikan kawasan agrowisata. Komoditas buah-buahan dan bunga yang bisa dikembangkan di Kedung Kayang antara lain : buah jeruk, buah melon, buah kesemek, 
bunga krisan dan bunga mawar.

Pengembangan potensi pertanian yang sudah ada menjadi modal besar untuk dijadikannya kawasan wisata Kedung Kayang menjadi agrowisata dan kualitas lingkungan menjadi modal penting yang harus dijaga dan dikelola mengingat pentingnya nilai kualitas lingkungan tersebut. Masyarakat atau petani setempat perlu diajak untuk selalu menjaga keaslian, kenyamanan, dan kelestarian lingkungannya.

Dari 141 responden, 41,37 \% mengenal kawasan Kedung Kayang sebagai kawasan potensi alam, berupa air terjun, pemandangan dan sungai. 19,31\% responden mengenal kawasan ini sebagai kawasan pertanian serta 15,17\% responden mengenal sebagai kawasan Bumi Perkemahan. Responden yang menyatakan Kedung Kayang sebagai kesatuan dengan Wisata yang lain sebanyak 15,86\%, sedangkan 5,51\% responden menyatakan sebagai potensi kegiatan kebudayaan masyarakat (Tabel 3). Mengingat beragamnya bentuk morfologi serta kondisi wilayah Kedung Kayang yang unik, berupa keragaman budaya atau adat yang berkembang disana dapat dijadikan sebagai potensi wisata.

Tabel 3. Potensi Kedung Kayang

\begin{tabular}{llcc}
\hline No. & \multicolumn{1}{c}{ Macam Potensi } & Jumlah & $\%$ \\
\hline 1. & Potensi Alam (air terjun, pemandangan, sungai) & 60 & 41,37 \\
2. & Potensi Pertanian & 28 & 19,31 \\
3. & Bumi Perkemahan & 22 & 15,17 \\
4. & Kesatuan dengan Wisata yang lainya & 23 & 15,86 \\
5. & Kegiatan-Kebudayaan Masyarakat & 8 & 5,51 \\
\hline
\end{tabular}

Dalam mengembangkan suatu kegiatan wisata perlu adanya hak pengelolaan kawasan wisata, baik dari pemerintah daerah, masyarakat setempat serta pengelola kawasan wisata Kedung Kayang.

\section{SIMPULAN}

1. Kedung Kayang memiliki potensi untuk dikembangkan menjadi kawasan agrowisata berupa air terjun, view Gunung Merapi, sungai, bentuk topografi dan bumi perkemahan.

2. Masyarakat Kedung Kayang mendukung pengembangan agrowisata di wilayahnya.

\section{DAFTAR PUSTAKA}

Disparbud Magelang. Dinas Pariwisata Budaya Magelang. 2002. kondisi pertanian Dalam www.magelang.go.id . 25 Juli 2007 Suwantoro,G.2002.Bentuk Wisata. Dalam http:// www. suaramerdeka.com. 2 Juni 2007 